\title{
KINERJA RAMBU LALU LINTAS DAN DAMPAKNYA PADA KECELAKAAN (STUDI KASUS : JALAN SOEKARNO HATTA BANDUNG)
}

\author{
Yusmiati Kusuma ${ }^{1}$, Tatang Sumarna ${ }^{2}$, Dewi Mustika ${ }^{3}$, Melina Demar $^{4}$ \\ ${ }^{1}$ Dosen Jurusan Teknik Sipil, Politeknik Negeri Bandung, Bandung 40012 \\ E-mail:metty@polban.ac.id \\ ${ }^{2}$ Dosen Jurusan Teknik Sipil, Politeknik Negeri Bandung, Bandung 40012 \\ E-mail:tatangsumarnal@yahoo.com \\ ${ }^{3}$ Lulusan Program Studi Teknik Konstruksi Sipil, Jurusan Teknik Sipil, Politeknik Negeri Bandung, Bandung 40012 \\ E-mail:dmustika4@gmail.com \\ ${ }^{3}$ Lulusan Program Studi Teknik Konstruksi Sipil, Jurusan Teknik Sipil, Politeknik Negeri Bandung, Bandung 40012 \\ E-mail:melindemart98@gmail.com
}

\begin{abstract}
ABSTRAK
Jalan Soekarno Hatta merupakan jalan arteri primer yang sering terjadi kecelakaan. Lokasi kecelakaan paling tinggi di Jalan Soekarno berdasarkan penelitian sebelumnya (2018) terdapat pada 2 STA. Salah satu upaya untuk menekan jumlah kecelakaan berdasarkan faktor lingkungan dengan memasang rambu lalu lintas pada jalan yang rawan kecelakaan. Sehingga dilakukan terhadap standardisasi identifikasi rambu yang terpasang berdasarkan PM No.13 Tahun 2014 dan pengujian tingkat retroreflektifitas rambu dengan menggunakan alat RetroSign berdasarkan ASTM D4956-04. Rambu yang terpasang di 2 STA tersebut berjumlah 14 buah rambu dengan persentase rambu yang memenuhi standardisasi rambu lalu lintas sebesar $28,57 \%$ dan persentase tingkat retroreflektifitas rambu sebesar $7,14 \%$.
\end{abstract}

Kata Kunci: Rambu Lalu Lintas, Retrosign, Retroreflektifitas

\section{ABSTRACT}

The Soekarno Hatta Road is a primary arterial road that often crashes. The highest accident location on Jalan Soekarno based on previous research (2018) is at 2 STA. One effort to reduce the number of accidents based on environmental factors is by installing traffic signs on road that is prone to accidents. So it was carried out on standardization of the identification of attached signs based on PM No. 13 of 2014 and testing the level of retroreflectivity of the signs using RetroSign tools based on ASTM D4956-04. Signs that are installed in the 2 STA are 14 signs with the percentage of signs that meet the traffic sign standardization of $28,57 \%$ and the percentage of signs retroreflective level of $7,14 \%$.

\section{PENDAHULUAN}

Bandung merupakan Ibu Kota Provinsi Jawa Barat yang memiliki populasi cukup padat. Berdasarkan data Badan Pusat Statistik (BPS) tahun 2016 tercatat bahwa penduduk Kota Bandung berjumlah 3.596.623 jiwa. Untuk memfasilitasi penduduk Kota Bandung tersebut, maka disediakanlah sarana transportasi. Dimana sarana transportasi ini sangat dibutuhkan banyak orang untuk melaksanakan aktivitasnya. Kota Bandung memiliki 10 jalan arteri primer salah satu jalan arteri primer yang memenuhi kriteria PP RI No.34/2006 adalah Jalan Soekarno Hatta. Jalan Soekarno Hatta adalah salah satu jalan arteri terpanjang di Kota Bandung. Jalan Soekarno Hatta memiliki panjang $18,46 \mathrm{Km}$ dengan batas dari bundaran Cibereum sampai dengan bundaran Cibiru.

Jalan arteri primer memiliki risiko tingkat kecelakaan yang tinggi. Kecelakaan lalu lintas tersebut terus berubah dan penyebab kecelakaan disebabkan oleh beberapa faktor seperti manusia, kendaraan itu sendiri, jalan dan lingkungan di sekitarnya. Kecelakaan di Jalan Soekarno Hatta sering terjadi karena faktor manusia dan faktor jalan dan lingkungan. Berdasarkan data yang didapat dari lakalantas Kota Bandung pada tahun 2015 sampai 2017 di jalan Soekarno Hatta telah terjadi kecelakaan lalu lintas sebanyak 254 kejadian. Kecelakaan pada tahun 2015 sebanyak 73 kejadian, tahun 2016 sebanyak 104 kejadian, dan tahun 2017 sebanyak 78 kejadian. Faktor penyebab kecelakaan pada Jalan Soekarno Hatta tahun 2015 sampai tahun 2017 adalah 192 faktor manusia dan 63 faktor jalan dan lingkungan. Dari total jumlah faktor penyebab kecelakaan tersebut, didapatkan persentase faktor manusia sebesar $80,06 \%$ dan persentase faktor jalan dan lingkungan sebesar $19,94 \%$.

Kecelakaan tertinggi di Jalan Soekarno Hatta terdapat pada STA $10+000-11+000$ STA $15+000-16+000$ dari 18 segmen (Kukuh dan Satria 2018). Pada STA 10+000 - 
11+000 dengan jumlah kecelakaan 21 kecelakaan dan STA $15+000-16+000$ dengan jumlah kecelakaan 20 kecelakaan. Kecelakaan itu terjadi karena kurangnya rambu yang terpasang di tempat yang rawan kecelakaan. Sebelum memasang rambu yang mungkin dibutuhkan, maka terlebih dahulu dilakukan penilaian terhadap kondisi rambu eksisting sesuai dengan standardisasi rambu dan melakukan penilaian terhadap tingkat retroreflektifitas dari rambu yang terpasang di Jalan Soekarno Hatta. Penilaian tersebut dilakukan dengan menggunakan alat RetroSign. Sehingga untuk menekan jumlah kecelakaan yang terus meningkat, maka dilakukan penelitian mengenai kinerja rambu lalu lintas tersebut dan dampaknya pada kecelakaan yang terjadi di Jalan Soekarno Hatta Kota Bandung..

\section{STUDI PUSTAKA}

Menurut Peraturan Menteri Perhubungan Republik Indonesia No.13 Tahun 2014, Rambu Lalu Lintas adalah bagian perlengkapan Jalan yang berupa lambang, huruf, angka, kalimat, dan/perpanduan yang berfungsi sebagai peringatan, larangan, perintah, atau petunjuk bagi pengguna jalan.

Berdasarkan jenisnya rambu terbagi menjadi empat, yaitu rambu peringatan, rambu larangan, rambu perintah, dan rambu petunjuk.

Persyaratan rambu berdasarkan jarak penempatan sebelah kiri rambu Lalu Lintas ditempatkan di sebelah kiri menurut arah lalu lintas pada jarak tertentu dari tepi paling luar bahu jalan atau jalur lalu lintas kendaraan dan tidak merintangi lalu lintas kendaraan atau pejalan kaki. Rambu Lalu Lintas ditempatkan pada jarak paling sedikit 0,6 meter diukur dari bagian terluar daun rambu ke tepi paling luar bahu jalan. Persyaratan rambu lalu lintas sebelah kanan, dalam hal lalu lintas satu arah dan tidak ada ruang pemasangan lain, rambu lalu lintas dapat ditempatkan di sebelah kanan menurut arah lalu lintas. Rambu Lalu Lintas dapat dipasang pada pemisah jalan (median) dan ditempatkan dengan jarak paling sedikit 0,3 meter diukur bagian terluar daun rambu ke tepi paling luar kiri dan kanan dari pemisah jalan.

Persyaratan tinggi rambu-rambu lalu lintas ditempatkan pada sisi jalan paling tinggi 2,65 meter dan paling rendah 1,75 meter diukur dari permukaan jalan tertinggi sampai dengan sisi daun rambu bagian bawah.

Retroreflektif adalah sistem pemantulan cahaya dimana sinar yang datang dipantulkan kembali sejajar ke arah sinar datang, terutama pada malam hari atau cuaca gelap.

Berdasarkan ASTM D4956-04 lembaran retroreflektif ada 10 tipe, yaitu:

1. Lembaran retroreflektif tipe I

2. Lembaran retroreflektif tipe II

3. Lembaran retroreflektif tipe III
4. Lembaran retroreflektif tipe IV

5. Lembaran retroreflektif tipe $\mathrm{V}$

6. Lembaran retroreflektif tipe VI

7. Lembaran retroreflektif tipe VII

8. Lembaran retroreflektif tipe VIII

9. Lembaran retroreflektif tipe IX

10. Lembaran retroreflektif tipe $X$

Kecelakaan lalu lintas Menurut Hobbs 1979 kecelakaan disebabkan oleh 3 faktor, yaitu faktor pemakai jalan (manusia), faktor kendaraan, faktor jalan dan lingkungan..

\section{METODOLOGI}

Metodologi Secara umum tahapan pelaksanaan penelitian ini disajikan dalam bentuk diagram alir agar mudah dipahami. Pada diagram alir dijelaskan tahapan-tahapan dalam pelaksanaan yang akan dilakukan mulai dari awal penelitian sampai mendapatkan hasil yang diinginkan seperti terlihat pada Gambar 1.

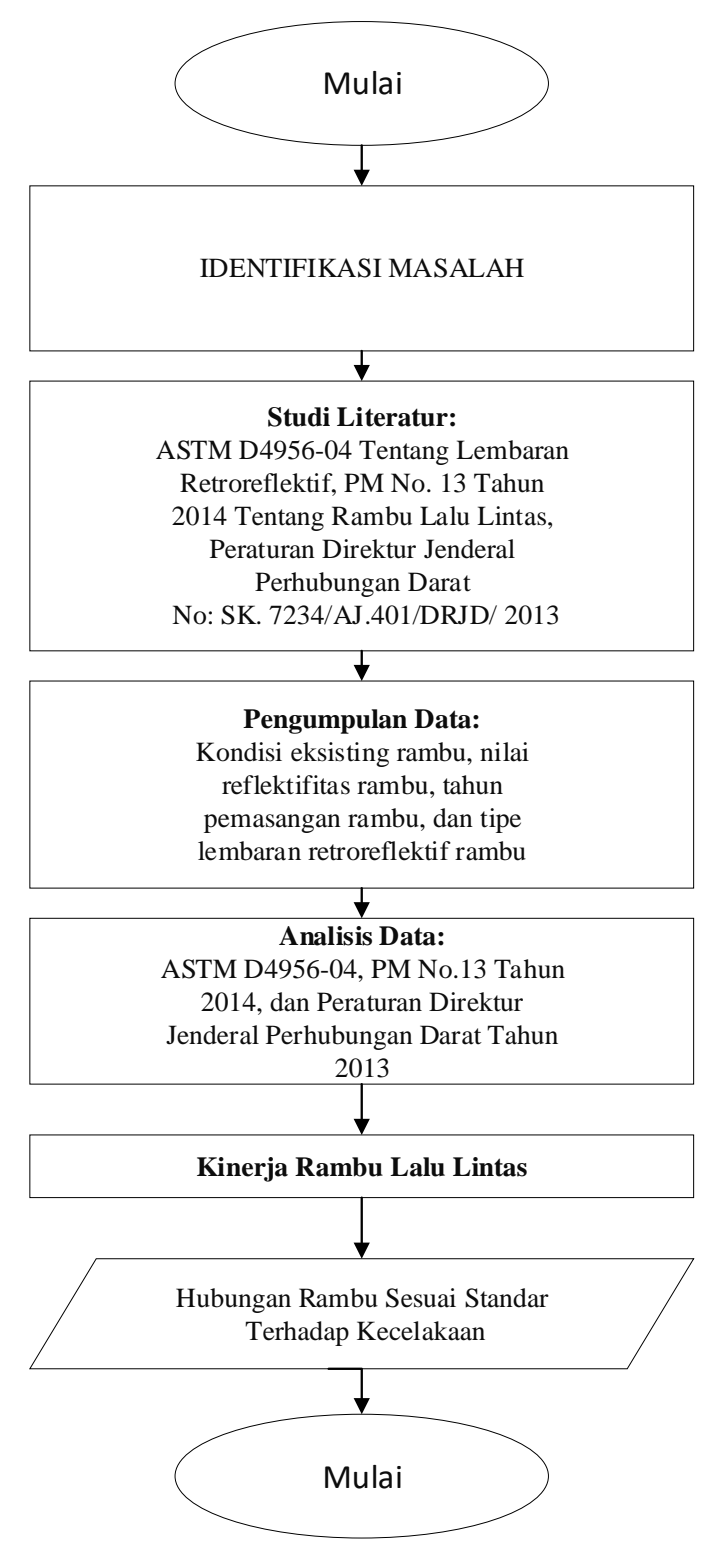

Gambar 1. Metodologi Pelaksanaan Penelitian 


\section{ANALISIS DAN PEMBAHASAN}

Hasil dari analisis rambu dapat diketahui bahwa tidak semua rambu yang terpasang pada lokasi pengujian sesuai dengan standarisasi berdasarkan Peraturan Menteri Perhubungan Republik Indonesia Nomor 13 Tahun 2014. Berikut ini adalah jumlah rambu yang masih layak terpasang di 2 STA pada Tabel 1.

Tabel 1. Jumlah Rambu Yang Memenuhi Standarisasi di 2 STA

\begin{tabular}{|c|c|c|}
\hline Nama STA & $\begin{array}{c}\text { Jumlah } \\
\text { Rambu Yang } \\
\text { Terpasang }\end{array}$ & $\begin{array}{c}\text { Jumlah Rambu } \\
\text { Yang Memenuhi } \\
\text { Standardisasi }\end{array}$ \\
\hline $10+000-11+000$ & 3 & 0 \\
\hline $15+000-16+000$ & 11 & 4 \\
\hline Total & 14 & 4 \\
\hline
\end{tabular}

Dari Tabel 1 didapat hanya 4 rambu yang memenuhi standarisasi berdasarkan Peraturan Menteri Perhubungan Republik Indonesia Nomor 13 Tahun 2014 dari jumlah keseluruhan rambu yaitu 14 buah. Perhitungan persentase rambu yang sesuai standardisasi yaitu (4/14) * $100=$ 28,57\%. Diagram persentase dapat dilihat pada Gambar 2 berikut ini.

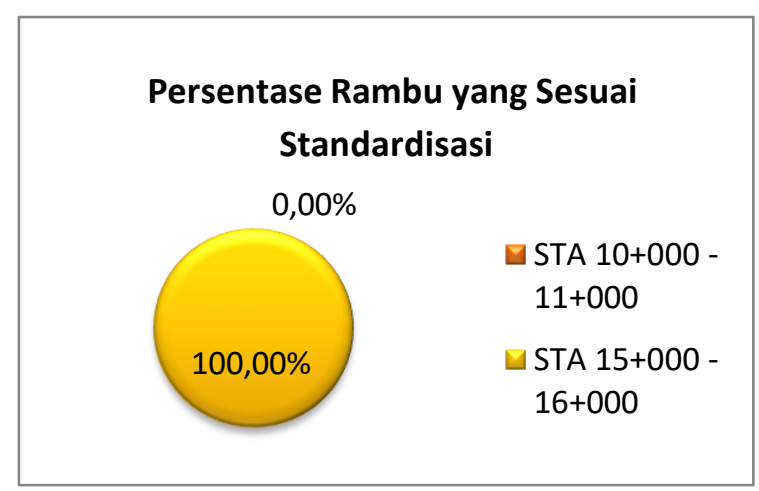

Gambar 2. Diagram Persentase Rambu yang Sesuai Standardisasi

Berdasarkan diagram tersebut persentase paling besar terdapat pada STA $15+000-16+000$ yaitu $100 \%$. Untuk persentase paling kecil terdapat pada STA 10+000 $11+000$ yaitu $0 \%$.

Hasil dari analisis nilai tingkat retroreflektifitas rambu dapat diketahui bahwa tidak semua rambu yang terpasang pada lokasi pengujian sesuai dengan ASTM D4956-04. Berikut ini adalah jumlah rambu yang masih layak terpasang di 2 STA pada Tabel 2.
Tabel 1. Jumlah Rambu Berdasarkan Tingkat Retroreflektifitas di

\begin{tabular}{|c|c|c|}
\hline \multicolumn{3}{|c|}{5 STA } \\
$\begin{array}{c}\text { Nama } \\
\text { STA }\end{array}$ & $\begin{array}{c}\text { Jumlah } \\
\text { Rambu Yang } \\
\text { Terpasang }\end{array}$ & $\begin{array}{c}\text { Jumlah Rambu } \\
\text { Yang Memenuhi } \\
\text { Tingkat } \\
\text { Retroreflektifitas } \\
\text { Berdasarkan ASTM } \\
\text { D4956-04 }\end{array}$ \\
\hline $\begin{array}{c}10+000- \\
11+000\end{array}$ & 3 & 0 \\
\hline $\begin{array}{c}15+000- \\
16+000\end{array}$ & 11 & 1 \\
\hline Total & 14 & 1 \\
\hline
\end{tabular}

Dari tabel tersebut didapat hanya 1 rambu yang memenuhi standarisasi tingkat retroreflektifitas berdasarkan ASTM D4956-04 dari jumlah keseluruhan rambu yaitu 14 buah. Untuk Perhitungan persentase tingkat retroreflektifitas rambu yaitu $(1 / 14) * 100=7,14 \%$. Persentase tingkat retroreflektifitas rambu yang memenuhi standardisasi yang terpasang pada 2 STA tersebut adalah 7,14\%. Diagram persentase dapat dilihat pada Gambar 3 berikut.

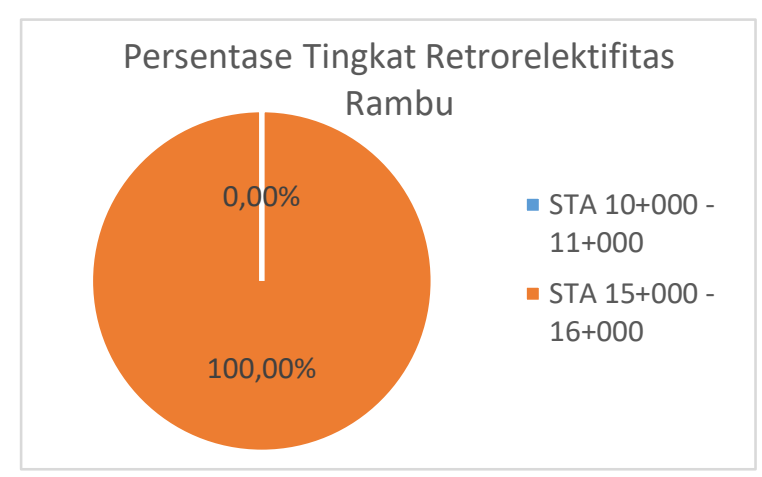

Gambar 3. Diagram Persentase Tingkat Retroreflektifitas Rambu

Berdasarkan diagram tersebut persentase paling tinggi terdapat pada STA $15+000$ - 16+000 dengan persentase $100 \%$. Sedangkan persentase paling kecil terdapat pada STA $10+000-11+000$ dengan persentase $0 \%$.

Berdasarkan hasil klasifikasi rambu yang sesuai dengan standar dihubungkan dengan tingkat kecelakaan dapat dilihat pada Gambar 4.

Dari Gambar 4 jumlah kecelakaan tertinggi mempunyai jumlah rambu terkecil yang sesuai dengan standar terdapat pada STA 10+000 -11+000. Dan pada jumlah kecelakaan terendah mempunyai jumlah rambu yang terbanyak yang sesuai dengan standar terdapat pada STA $15+000-16+000$.

Berdasarkan hasil klasifikasi rambu yang masih reflektif dihubungkan dengan tingkat kecelakaan dapat dilihat pada Gambar 5. 


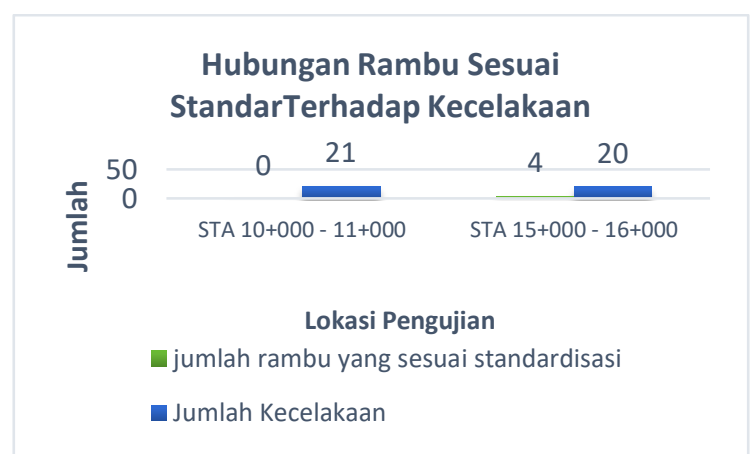

Gambar 4. Hubungan Rambu yang Sesuai Standar Terhadap Kecelakaan

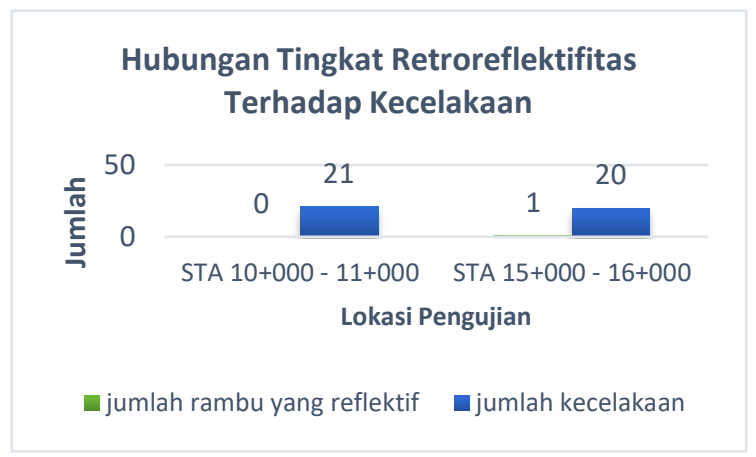

Gambar 5. Hubungan Rambu yang Masih Reflektif Terhadap Kecelakaan

Dari Gambar 5 jumlah kecelakaan tertinggi dengan rambu yang masih reflektif terkecil yang sesuai dengan standar terdapat pada STA $10+000-11+000$.

Berdasarkan rambu yang sesuai standar dan rambu yang masih reflektif paling kecil dengan jumlah kecelakaan tertinggi terdapat pada STA10+000 -11+000.

\section{KESIMPULAN}

1. Berdasarkan standardisasi rambu pada 2 STA yang ditinjau pada Jalan Soekarno Hatta Bandung terdapat 4 buah rambu yang memenuhi standardisasi dari 14 buah rambu yang terpasang.

2. Tingkat retroreflektifitas rambu pada Jalan Soekarno Hatta dengan alat RetroSign yang memenuhi ASTM D4956-04 yaitu ada 1 buah rambu dari 14 buah rambu yang dipasang pada 2 STA yang ditinjau.

3. Dari hasil analisis didapat rambu yang memenuhi standardisasi rambu dari 2 STA tersebut $28,57 \%$ dan persentase tingkat retroreflektifitas rambu yang masih memenuhi standarisasi pada 2 STA yaitu 7,14\%.

4. Berdasarkan rambu yang sesuai standar dan rambu yang masih reflektif paling kecil dengan jumlah kecelakaan tertinggi terdapat pada STA10+000 -11+000.

\section{DAFTAR PUSTAKA}

[1]. _. Kamus Besar Bahasa Indonesia

[2]. ASTM D4956-04. Standard Specification For Retroreflective Sheeting For Traffic Control.

[3]. Badan Pusat Statistik (2016): Proyeksi Jumlah Penduduk Provinsi Jawa Barat, https://jabar.bps.go.id/dynamictable/2016/10/06/15/proyeksi -jumlah-penduduk-provinsi-jawa-barat-2010-2016.html Download (diturunkan/diunduh) pada 21 Februari 2019.

[4]. Budiarsi, Kukuh dan Muhamad Satria Maulana. 2018. Pengkajian Karakteristik Kecelakaan Pada Jalan Soekarno Hatta Kota Bandung. Bandung: Jurusan Teknik Sipil Politeknik Negeri Bandung.

[5]. Departemen Perhubungan Direktorat Jenderal Perhubungan Darat Direktorat Bina Sistem Transportasi Perkotaan. Panduan Penempatan Fasilitas Perlengkapan Jalan.

[6]. Kementerian Perhubungan Direktorat Jenderal Perhubungan Darat Direktorat Lalu Lintas dan Angkutan Jalan. 2013. Peraturan Direktur Jenderal Perhubungan Darat Nomor. SK.7234/AJ.401/DRJD/2013 Tentang Petunjuk Teknis Perlengkapan Jalan.

[7]. Hobbs, F., D. 1973. Traffic Engineering: Theory \& Practice, Pentice Hall, Englewood Cliffs,N.J.

[8]. Oktaviani, Haryati Dwi dan Marina Eka Wulandari. 2018. Identifikasi Faktor Penyebab Kecelakaan Pada Ruas Jalan Arteri Primer Kota Bandung. Bandung: Jurusan Teknik Sipil Politeknik Negeri Bandung.

[9]. Peraturan Menteri Perhubungan Republik Indonesia Nomor 13 Tahun 2014 Tentang Rambu Lalu Lintas.

[10]. Pemerintah Republik Indonesia Nomor 43. 1993. Peraturan Pemerintah Nomor Tentang Prasarana dan Lalu Lintas Jalan. Jakarta.

[11]. Peraturan Pemerintah Republik Indonesia Nomor 34. 2006. Jalan. Jakarta

[12]. U.S. Department of Transportation Federal Highway Administration. https://safety.fhwa.dot.gov/roadway_dept/night_visib/retroto olkit/pdfs/measurement.pdf. Download (diturunkan/diunduh) pada 23 Februari 2019 